\title{
O computador como proposta para superar dificuldades de aprendizagem: estratégia ou mito?
}

\section{The computer as purpose to overcoming learning difficulties: strategy or mithe?}

\author{
Keite de Melo Nepomuceno* \\ Mônica Rabello de Castro**
}

\begin{abstract}
RESUMO
O objetivo deste estudo foi investigar as concepções de dificuldades de aprendizagem de sujeitos envolvidos em programas que utilizam o computador, buscando identificar as expectativas que depositam no recurso tecnológico para a superação do problema. Investigaram-se três programas, num total de doze entrevistas, classificando os sujeitos em três categorias: professor, instrutor e coordenador da proposta. Dois programas funcionavam em escolas públicas, uma do Rio de Janeiro e outra da Baixada Fluminense, e o terceiro em uma escola particular da Zona Sul do Rio de Janeiro. A análise dos dados foi baseada no Modelo da Estratégia Argumentativa. O confronto dos discursos em um mesmo programa revelou distanciamentos, contradições e poucas aproximações: para alguns, não existe dificuldade de aprendizagem; para outros, a dificuldade não é da criança; e, para outros ainda, a dificuldade é da criança e está relacionada a questões psicológicas passíveis de complexas classificações. O computador aparece ora como mero motivador, ora como meio de disciplinar o aluno, ora como meio de expressão e parte do processo ensino-aprendizagem. A existência de conflitos entre as concepções reflete um não-consenso entre os envolvidos, acarretando efeitos impeditivos aos objetivos pretendidos pelos programas.

Palavras-chave: concepções de dificuldade de aprendizagem, computador na educação, estratégia argumentativa.

\footnotetext{
* Universidade Estácio de Sá. E-mail: keitemelo@ig.com.br.

** Universidade Estácio de Sá. E-mail: rabellomonica@uol.com.br.
} 


\begin{abstract}
The aim of this study was to investigate the conceptions of learning difficulties of individuals involved in programs that use computer searching to identify their expectations about the technological resource to overcome such problem. Three programs have been investigated, compiling a sum of twelve interviews, which classify the individuals into three classes: teacher, instructor and the coordinator of the proposal. Two programs were developed in public schools, one in Rio de Janeiro, another one in Baixada Fluminense, and the third one in a private school situated in the South of Rio de Janeiro. The analysis of the data was based on the Argumentative Strategy Model. The discourse faced in the same program showed fares, contradictions and a few approaches: for some individuals, the learning difficulties don't exist. For others, the difficulty is not from the child; yet others consider that the child's difficulty is related to psychological matters open to complex classifications. The computer appears just one time as an inducement, at another moment as a way to discipline the student, and also as a way of expression and part of the learning and teaching process. The existence of conflicted conceptions reflect a lack of agreement among them, causing hindrance in relation to the intended objectives of such program. Key words: difficulty in learning conceptions, computer in education, argumentative strategy.
\end{abstract}

\title{
Introdução
}

Muitas são as contribuições da comunidade acadêmica quanto aos temas dificuldade de aprendizagem e fracasso escolar; no entanto, essas contribuições não têm alterado de forma significativa o quadro excludente na educação. Surgem, então, programas que se propõem a superar as dificuldades através de ações compensatórias: classes especiais, classes de aceleração, reforço escolar, aumento das horas-aula para um grupo específico de alunos e, mais recentemente, programas que acenam para a superação do problema através da adoção do computador.

No início dos anos de 1980, várias foram as iniciativas de uso da informática na Educação no Brasil, despertando o interesse do governo e de pesquisadores das universidades na adoção de programas educacionais com o uso de tal ferramenta. Segundo Valente (1989), as propostas pedagógicas da Informática na Educação no Brasil sempre foram baseadas nas pesquisas realizadas com parceria entre as universidades e escolas da rede pública, ou seja, sobre experiências concretas, da realidade da grande maioria das crianças brasileiras. 
Em plena era tecnológica, na qual a adoção da informática na educação multiplica-se pelo nosso imenso país em escolas públicas, ainda estamos engatinhando na formação do cidadão capaz de enfrentar as exigências que se apresentam no mundo moderno.

Acontece que as iniciativas visando à superação do problema das dificuldades de aprendizagem não têm se mostrado eficazes, sendo geralmente motivadas por interesses em diminuir o impacto negativo do desempenho da escola pública nos resultados de avaliações nacionais como as do SAEB (Sistema Nacional de Avaliação da Educação Básica) e do ENEM (Exame Nacional do Ensino Médio). Observa-se que, nessas iniciativas, o currículo não foi alterado, os métodos de ensino são os mesmos e também são idênticos: os critérios de avaliação, aprovação e objetivos de aprendizagem.

Tendo em vista a crescente proliferação de projetos que utilizam o computador como tecnologia na educação, e o financiamento que recebem tais projetos, podemos inferir um certo otimismo quanto ao papel da informática na educação, como se o computador, por si só, ao modernizar a escola, pudesse transformar o quadro educacional.

As dificuldades de aprendizagem são abordadas pela literatura sob diversos enfoques: psicológico, neurológico, biológico, fonoaudiológico, pedagógico e social. Embora haja relevantes contribuições, o problema continua se agravando e, num certo sentido, acaba sendo ocultado ou mesmo mascarado por tentativas de suavizar índices de repetência através de condições de ensino menos exigentes, conteúdos reduzidos e duvidosas adaptações do currículo às condições dos alunos.

Os programas que utilizam o computador para superar dificuldades de aprendizagem possuem pelo menos três categorias de sujeito neles envolvidos diretamente: o coordenador do programa (quem escreveu e concebeu o projeto), o professor do aluno (quem identifica e seleciona alunos com dificuldade de aprendizagem) e o instrutor (sujeito responsável por aplicar de forma mais efetiva a proposta). Os sujeitos envolvidos nos programas podem ter diferentes pontos de vista acerca do que seja dificuldade de aprendizagem, sobre a eficácia pretendida pelo programa com o uso do computador, sobre a capacidade de o aluno vir a superar a dificuldade, e mesmo se o aluno selecionado pelo seu professor possui realmente dificuldade ou é vítima da inadequação de metodologia pedagógica.

Nossa proposta de investigação foi analisar as concepções das três categorias de sujeitos, participantes de três diferentes programas, quanto à utilização da ferramenta computacional para superar ou diminuir dificuldades de aprendizagem, destacando possíveis conflitos e/ou distanciamentos entre as concepções, principalmente no que diz respeito aos resultados esperados ou 
alcançados pelos respectivos programas. Acreditamos que o distanciamento das concepções dos envolvidos no programa pode alterar de forma significativa a ação pedagógica pretendida. Propostas são experimentadas e concretizadas tendo em vista superar as dificuldades de aprendizagem; mas, se não apresentam resultados com impacto significativo, acabam por desperdiçar o investimento de recursos públicos e o tempo dos alunos nele enquadrados.

\section{Concepções de dificuldades de aprendizagem}

A escola não tem sido competente no ensino do mais básico em educação: ler, escrever e contar. Essa incompetência gera o fracasso escolar e acentua desigualdades sociais. Pesquisas (CARVALHO, 1996; GOMES, 2002; SILVA, 2002; SOARES, 1997; WEISS, 2001) sinalizam que o aluno concebido pelo seu professor como portador de dificuldades de aprendizagem tende, quase que inevitavelmente, ao fracasso escolar.

No estudo de Alves-Mazzotti (2003) quanto às representações sociais de professores sobre o fracasso escolar, a autora concluiu que fazem parte das representações dos professores associadas à repetência, hierarquicamente, as "dificuldades de aprendizagem", seguida pela "falta de apoio da família" e em terceiro lugar a "baixa na auto-estima", "desinteresse" e "pobreza familiar". Esses elementos, que constituem o núcleo central das representações na visão dos professores investigados, é que levam o aluno à repetência.

O que o professor entende por dificuldade de aprendizagem, se ele aponta esta como o primeiro elemento associado à repetência?

O conceito de dificuldade de aprendizagem é trabalhado há bastante tempo, porém não há sobre ele um consenso na literatura, a qual oferece diferentes enfoques oriundos de diversas áreas do conhecimento. Também são oferecidas diversas nomenclaturas (CARVALHO, 1996, p. 168) para o problema: distúrbio de aprendizagem, que sugere uma patologia no processo de aprendizagem, muda-se então para dificuldade de aprendizagem ou problema de aprendizagem e, por último, portador de necessidades educativas, o que remete imediatamente à Educação Especial e aos portadores de deficiência. Aqui, utilizamos a expressão "dificuldade de aprendizagem" (DA), uma vez que os sujeitos dos três programas investigados também se utilizaram do termo para expressar o problema da não-aprendizagem. 
Alves-Mazzotti (2003, p. 2) denuncia que a própria literatura sobre "fracasso escolar" das crianças pobres está permeada de preconceitos e estereótipos. É essa mesma literatura que faz parte dos cursos de formação de professores e possivelmente vem alimentando crenças e orientando práticas educacionais.

Gomes (2002, p. 14-26) aponta as seguintes teorias como as que responsabilizam o aprendiz e/ou sua família pela DA:

- Teoria do "handicap sociocultural" - surgida nos anos de 1960, nos Estados Unidos, defende a "superioridade" do controle cultural das classes dominantes, em confronto com a "pobreza cultural" do contexto em que vivem as classes dominadas. O contexto é que é responsável pelos "déficits" das crianças de camadas populares que se vêem privadas de alimentação, atenção, cultura, apresentando "carências", sobretudo no campo intelectual;

- Teoria organicista - surge na França, no século XIX, da literatura médica e localiza as causas das dificuldades de aprendizagem no cérebro. Alguns estudiosos defendem que tais dificuldades são inatas, outros que são adquiridas e ainda há aqueles que não entram na polêmica do inato/adquirido e localizam-nas na não-maturação do sistema nervoso central. Os problemas de aprendizagem recebem uma classificação médica.

Essa teoria facilitava a aceitação do aluno pela escola, visto ser portador de uma patologia, mas, ao mesmo tempo, desmotivava os educadores a investirem nele e acabavam por perceber a criança como vítima de um mal irreversível. Criava-se, então, um estado de acomodação diante da suposta "doença" da criança.

- Teoria cognitivista - aparece e se desenvolve na França, nos Estados Unidos e na Grã-Bretanha, logo depois da $2^{\mathrm{a}}$ Guerra Mundial. Nasceu da Psicologia e pretendeu fazer a crítica à concepção organicista. Busca as origens das dificuldades de aprendizagem na inteligência, na percepção, na integração de sentidos auditivos e visuais, na memória imediata, na atenção seletiva, na linguagem, em transtornos de desorganização espaço-temporal, ou seja, naquilo que ela denomina "déficits" cognitivos, sempre relativos ao indivíduo.

Ainda sobre as teorias que responsabilizam o aluno e sua família pelas dificuldades de aprendizagem, Soares (1997, p. 10-12) relaciona as seguintes ideologias: 
- Ideologia do dom - com origem na Psicologia Diferencial e na Psicometria, legitima desigualdades e diferenças pela mensuração de aptidões intelectuais (aptidão verbal, numérica, espacial, etc.) de prontidão para a aprendizagem, de inteligência ou de quociente intelectual (QI) etc., através de testes, escalas, provas, aparentemente "objetivos", "neutros", "científicos". Essas desigualdades e diferenças individuais, assim legitimadas, é que explicariam as diferenças do rendimento escolar.

Alguns educadores justificam as dificuldades escolares como falta de capacidade, pré-requisitos ou habilidades que ainda não se desenvolveram. A ideologia do dom ainda conta com um número grande de adesões por parte dos educadores.

- Ideologia da deficiência cultural - postula que os alunos provenientes das classes dominadas têm maior probabilidade de fracasso na escola: pertenceriam a essas classes exatamente por serem menos dotados, menos aptos, menos inteligentes. Quando bem-dotados e inteligentes, não fracassariam e teriam fácil acesso às classes dominantes.

- Ideologia das diferenças culturais - postula a existência de uma diversidade de "culturas", diferentes umas das outras, mas todas igualmente estruturadas, coerentes, complexas (SOARES, 1997, p.14). Como a escola valoriza a cultura das classes dominantes, o aluno da classe popular sofre um processo de "marginalização cultural" e acaba por fracassar, pois possui uma cultura diferente da privilegiada, seu dialeto não é o padrão.

A "ideologia da deficiência cultural" aproxima-se da teoria do "handicap sociocultural" relacionada por Gomes (2002). Os autores que tratam das categorizações da dificuldade de aprendizagem concluem que a escola tem se utilizado da condição socioeconômica do aluno para o classificá-lo como portador de dificuldade de aprendizagem.

Castanheira e Santiago (2004) complementam, relacionando mais duas abordagens que explicam a origem do fracasso escolar e orientam os profissionais (médicos, professores, supervisores, psicólogos, etc.) nos estudos e atendimentos a crianças com DA: 
- Abordagem Afetiva - busca explicação nos transtornos afetivos da personalidade. A dificuldade de aprendizagem estaria relacionada a perturbações no estado socioafetivo da criança, geralmente com origem na dinâmica familiar.

- Abordagem Questionamento da Escola - nessa abordagem a culpa recai sobre a escola e o professor. São apontados os seguintes problemas como intervenientes: inadequação dos métodos pedagógicos, dificuldades na relação professor-aluno, precária formação do professor, falta de infra-estrutura da escola pública.

Essa última abordagem inicia uma nova visão do problema das dificuldades de aprendizagem, que tem se refletido na busca por parte dos educadores de um eixo pedagógico para explicá-las, evidenciando uma não-aceitação de lidar apenas com o eixo clínico. No entanto, essa abordagem apenas transfere a culpa do aluno e da família para a escola e o professor.

Acreditamos que as dificuldades de aprendizagem precisam ser entendidas pelos diversos profissionais que trabalham com crianças, que eles crêem ser portadoras do problema, como um processo mutável, reversível e multidisciplinar.

\section{Metodologia}

Nossa proposta de investigação foi analisar as concepções quanto à utilização da ferramenta computacional para superar ou diminuir "dificuldades de aprendizagem", destacando possíveis conflitos e/ou distanciamentos entre elas. Suspeitávamos que cada sujeito tem hipóteses próprias em relação ao tema dificuldades de aprendizagem e a utilização do computador para superá-las, e que dirige suas ações baseado nessas hipóteses.

Neste artigo, apresentamos detalhadamente a análise das concepções de cada sujeito de um dos programas investigados, seguida do cruzamento dessas 
concepções, a fim de ilustrar como se deu a análise em cada programa. Dos demais programas, apresentamos apenas o cruzamento das concepções dos sujeitos. Embora os programas retratem realidades distintas, foi possível encontrar similaridades nos discursos, possivelmente pela influência de teorias, as quais buscamos tornar evidentes.

\section{O Modelo da Estratégia Argumentativa}

A maior parte das ações pedagógicas caracteriza-se como situações de diálogo. Sujeitos constroem suas concepções na interação com outros sujeitos. As concepções sobre DA são resultado de diversas negociações entre sujeitos envolvidos de algum modo com a questão.

Quando um sujeito distingue um aluno como portador de dificuldade de aprendizagem de um não-portador, ele o faz segundo suas crenças e só precisará justificar essas crenças se houver sobre elas controvérsia. Havendo controvérsia, terá que convencer seus pares da validade de suas crenças ou mudá-las. Quando um locutor constrói o seu discurso, ele leva em consideração o $\operatorname{argumento}^{1}$ de outrem e possíveis acordos ${ }^{2}$ entre ele e seus interlocutores. O objetivo do discurso passa pela intenção de convencer/persuadir um auditório ${ }^{3}$ de uma tese. Em muitas situações, necessariamente aquelas que envolvem controvérsias, a organização do discurso se dá por processos argumentativos.

O sucesso da argumentação depende da proximidade entre os acordos e premissas do interlocutor. Para Mazzotti e Oliveira (2000, p. 68), “... o orador só encontra eco para proposições que o auditório aceita”. Os autores definem os processos argumentativos como "mecanismos pelos quais os grupos sociais mantêm sua identidade, suas crenças, valores e assimilam novos conhecimentos". (MAZZOTTI e OLIVEIRA, 2000, p. 49).

Uma das formas utilizadas pelas pessoas para serem entendidas ou para dar força à sua argumentação é a metaforização. A metáfora evoca imagens do que queremos que se torne conhecido, a partir da "analogia entre os elementos que parecem comuns aos objetos (o conhecido e o ainda não conhecido)" (MAZZOTTI e OLIVEIRA, 2000, p. 52). Indivíduos utilizam-se das metáforas

${ }^{1}$ Argumento - elo que se estabelece entre enunciados com o intuito de persuadir.

${ }^{2}$ Premissas que são hipóteses do locutor a respeito das crenças do interlocutor.

${ }^{3}$ É o conjunto de todos aqueles sobre os quais o locutor quer exerce influência através do seu discurso. 
tanto para criticar quanto para tornar compreensível dado objeto ou fenômeno. Por esse motivo, a metáfora é um potente instrumento de identificação do sentido que os sujeitos projetam no mundo. (GAUTHIER, 2004, p. 132)

Castro et al. (2004, p.49) situam os processos de metaforização entre os mais importantes na produção dos sentidos: "A mente humana trabalha sempre no sentido da economia dos signos, da síntese das idéias, de armazená-las sob a forma de imagens que, quando evocadas, permitem ao falante organizar o sentido de sua expressão." Compreender as metáforas utilizadas para justificar crenças permite melhor compreender o sentido dessas crenças.

$\mathrm{Na}$ análise baseada no Modelo Estratégia Argumentativa, busca-se o que dá coerência às falas; busca-se na atividade em que o sujeito está engajado o sentido do que ele diz. Para a reconstrução de argumentos, representa-se através de esquemas o argumento usado pelo locutor, através de simples. A montagem de cada passo do argumento parte da identificação e da avaliação da inferência que originou a tese. Segundo Castro, Frant e Kindel (2001):

Os enunciados são traduzidos numa seqüência de perguntas-respostas e é a coerência dessa seqüência que nos permite compreender e avaliar um argumento. Busca-se não tanto significações aqui ou ali, mas aquilo que dá inteligibilidade e organização à fala.

A análise dos dados consistiu na reconstrução de estratégias argumentativas seguindo os seguintes passos: reconstrução de seqüências coerentes de raciocínio; preenchimento dos espaços implícitos; identificação dos significados relevantes; caracterização dos argumentos através de esquemas; interpretação desses esquemas. Procuramos por similaridades, oposições, contradições e conflitos, preenchendo os vazios deixados na argumentação. Procuramos também identificar as metáforas organizadoras de cada discurso.

Destacamos as duas questões de investigação por uma caixa de texto com sombreamento cinza. Para as metáforas utilizadas na argumentação, utilizamos caixa de texto com formato de nuvem, e os implícitos foram destacados por caixa de texto com linha tracejada. Nos esquemas, ligamos com um traço simples as idéias relacionadas e apontamos as oposições por meio de um X (xis). Para relacionar o discurso dos vários participantes de um mesmo programa e também entre uma mesma categoria de sujeitos dos vários programas, montamos novos esquemas, ressaltando as relações entre os diferentes aspectos dos discursos. 


\section{Os programas e sujeitos selecionados}

Programa 1: Efeitos da utilização do Ambiente Logo no atendimento à criança com dificuldade de aprendizagem. Esse programa teve início em novembro de 1997 e foi concluído em 1999. Tinha por propósito a utilização do computador para crianças com dificuldades de aprendizagem, nos campos da leitura, escrita e matemática, visando otimizar o aproveitamento escolar. Utilizamos para cada personagem uma nomenclatura específica para reconhecimento: Coord1 - Coordenador do programa 1, Inst1 - Instrutora do programa 1, Prof1A, Prof1B e Prof1C - Professoras regentes dos alunos do programa 1.

Programa 2: Classe de apoio à classe de alfabetização. A "classe de apoio" era uma turma formada por alunos de classe de alfabetização. Consideramos esse programa essencial tendo em vista que ele retrata uma escola de classe média-alta da zona sul do Rio de Janeiro. Foi importante conhecer as estratégias que utilizam com alunos, uma vez que as concepções de dificuldade de aprendizagem que mais ganham adesão no discurso docente são as relacionadas à carência econômica. Os sujeitos entrevistados foram: A2 - Assessor pedagógico do programa 2, Orient2 - Orientadora educacional do programa 2, Inst1 - Instrutora do programa 2, Prof2A e Prof2B - Professoras regentes dos alunos do programa 2.

Programa 3: Turma de projetos. Esse trabalho foi desenvolvido no decorrer do ano de 2003, em uma escola municipal da Baixada Fluminense, com uma turma do $3^{\circ}$ ano do ciclo de alfabetização. Retratada bem a realidade das escolas públicas no estado do Rio de Janeiro. A proposta é realizada em várias escolas da rede municipal, sob orientação e supervisão da Secretaria Municipal de Educação. Os sujeitos entrevistados foram: Inst3 - Instrutora do programa 3 e Prof3 - Professora do programa 3.

\section{Resultados}

Análise das entrevistas do Programa 1

Coordernadora do programa 1 - Coord1

$\mathrm{Na}$ argumentação da coordenadora, reconhecemos a metáfora do percurso como organizadora de sua fala. O diagnóstico de DA caracteriza o início de um 
trajeto, que é para ela dificuldade no padrão perceptivo e dificuldade espaçotemporal. O meio do trajeto é caracterizado pela presença do computador, que por si só trabalha a espaco-temporalidade e a atenção concentrada, concluindo que o trabalho foi certo, uma vez que funcionou em curto prazo. É importante pontuar que a preocupação com o espaço permeia toda a sua fala.

O esquema a seguir apresenta a organização da argumentação.

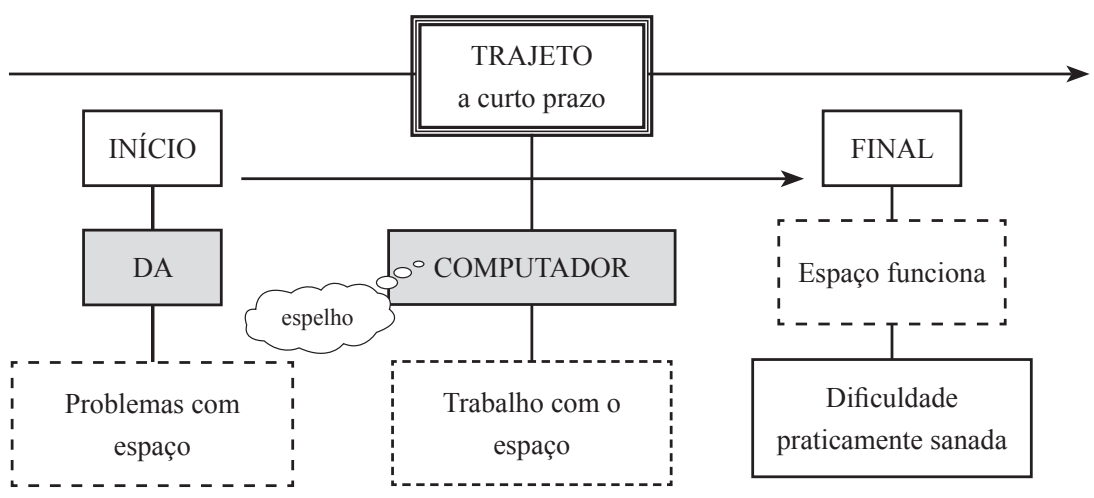

No início, havia a DA, e as crianças foram diagnosticadas apresentando dificuldades espaçotemporais, atenção dispersiva, lateralização cruzada, distúrbio de comportamento e problemas com padrão perceptivo, termos que denunciam a identificação da Coord1 com a concepção de DA da teoria cognitivista.

Segundo ela, o computador permitiu trabalho de espelhamento; a tela funcionou como um espelho. A presença da metáfora O COMPUTADOR É UM ESPELHO coloca em relevo as questões de lateralidade, uma vez que ela se refere à DA quase que exclusivamente como uma questão de organização do espaço, tendo utilizado para o

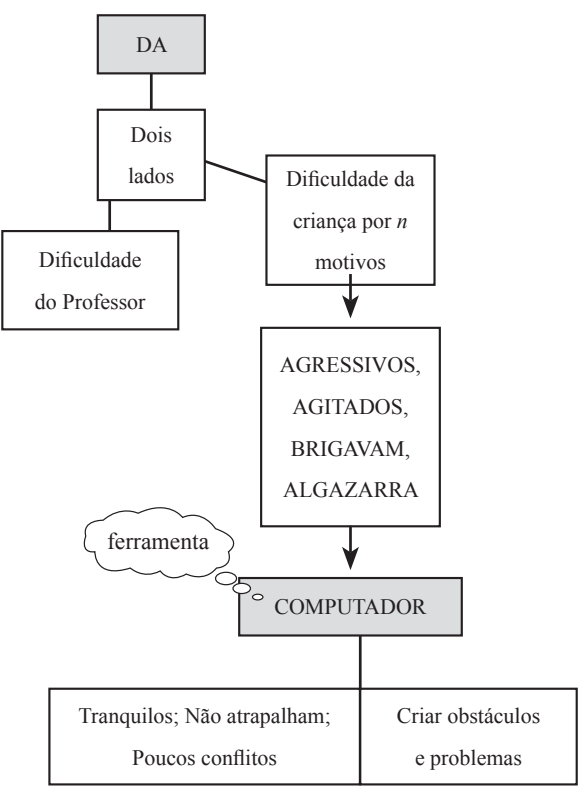


diagnóstico apenas o teste direita-esquerda piagetiano. Tudo se passa como se o computador, por si só, como um espelho, oferecesse à criança elementos para desenvolver sua lateralidade. Quem olha um espelho vê seu próprio corpo refletido; o computador e o trabalho com o corpo desenvolvem a cognição.

Fica implícito em sua fala que o problema inicial era com o espaço; o computador, o meio do trajeto, trabalha esse espaço e o final do processo é uma criança que domina o espaço.

\section{Instrutora do programa 1 - Inst1}

A instrutora era estagiária do programa e acompanhava os alunos no laboratório. Ela registrava no diário de campo o comportamento dos alunos diante do computador.

Em sua argumentação, aponta dois lados da DA: a dificuldade do professor e as dificuldades da criança. A dificuldade do professor é passar os conteúdos, pois hoje as crianças exigem mais. A outra dificuldade é a da criança, momento em que faz muitas menções às características comportamentais das crianças. Aponta a falta de comunicação na escola e a indisciplina como os motivos mais importantes que influenciam as dificuldades das crianças. Observe, no esquema, a quantidade de adjetivos usados por ela para se referir às crianças, imediatamente relacionadas a um quadro que podemos identificar como de indisciplina: agressividade, agitação, brigas, barulho e algazarra. A culpa das DAs é atribuída à escola e ao professor, como afirma a Abordagem questionamento da escola.

O computador é uma ferramenta problematizadora. No laboratório, as crianças ficavam mais disciplinadas. O fio condutor do seu discurso é a disciplina, embora sempre implícita em sua fala. O computador problematiza, cria desafios para as crianças. No laboratório, os alunos ficavam mais tranqüilos, não atrapalhavam e não havia tantos conflitos.

\section{Professora regente do programa 1 (Prof1A)}

Profl $A$ tinha em sua turma quatro alunos atendidos pelo programa. Em sua argumentação, identifica DA, quase que exclusivamente, com problemas disciplinares. O computador é um instrumento que ela utiliza como ameaça para conseguir o controle dos alunos.

Apenas quando questionada sobre orientação espacial e dificuldades de compreensão, é que a docente afirmou que eles também portavam esses problemas. No entanto, mesmo o problema da espacialidade estava vinculado à disciplina. 
Eu acho que todos estes alunos aqui têm problemas de orientação espacial. Eles não conseguem formar uma fila que não fiquem um em cima do outro.

Com a ajuda dos pais, que puniam em casa a seu pedido, e do computador, que ela utilizava como ameaça para controlar os alunos, foi possível observar uma melhora.

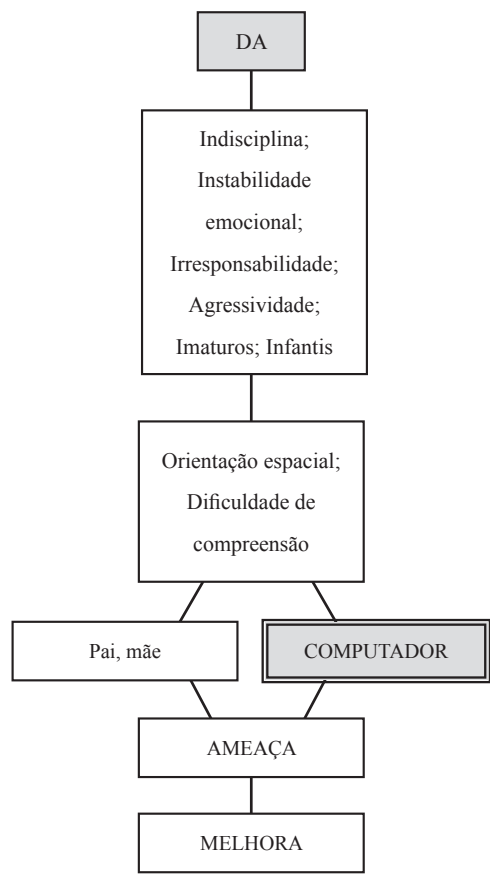

Todos eles gostam muito desse trabalho, então se a gente fizer ameaça, no bom sentido, para ver se eles se sacodem, se isso coopera, eles ficam com medo de não participar.

A questão econômica não foi abordada de forma explícita no discurso, mas é o que o fundamenta. Essas crianças vêm de uma cultura diferente, da classe popular. Para a professora, elas não sabem se comportar, são dispersas, têm dificuldade de compreender, entre outras coisas. Sua concepção de DA recebeu influência das teorias da deficiência cultural e da diferença cultural.

\section{Professora regente do programa 1 (ProflB)}

ProflB trabalha em dois turnos na escola, com a classe de aceleração. Essa classe utiliza livros diferentes das outras turmas e desenvolve atividades diversificadas. Para ela, a DA está diretamente ligada a problemas de comportamento: agressividade, agitação e depressão.

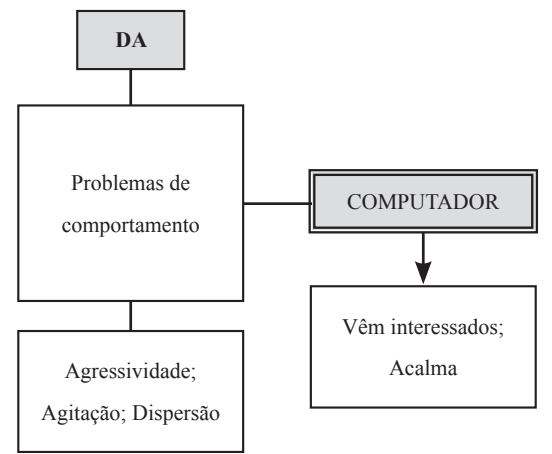


Todos são muito agressivos. A dificuldade se torna... o problema da dispersão e da agressividade.

O computador acalma as crianças. Elas ficam mais interessadas no dia em que participam do programa.

Esse tipo de trabalho (com o computador) acalma um pouco. Quando eles não vão, nossa... é uma coisa! [...] Eles chegam de lá com novidade, interessados nas atividades que desenvolveu e isso acaba refletindo no trabalho dentro da sala de aula.

Sua concepção de DA também sofreu influências das teorias da deficiência cultural e da diferença cultural. As falhas estão na família, na criança, em seu contexto cultural, que é pobre. As crianças não se adaptam às regras escolares. Vivem em ambientes com deficiência lingüística, o que acarreta deficiência cognitiva.

\section{Professora regente do programa 1 (Prof1C)}

ProflC tem em sua turma dois alunos que foram atendidos pelo programa. Para ela, a DA envolve vários fatores: tendência ao isolamento, aprendizado lento, dificuldade em leitura e interpretação e preguiça por parte do aluno.

O COMPUTADOR É UM PRÊMIO para essas crianças. Elas se sentem orgulhosas de participar do programa. A metáfora ressalta o caráter de dádiva, de doação que o computador significa, não só para as crianças mas para ela própria, que vê nele um aliado tanto para a questão do comportamento quanto da motivação. É importante ressaltar que, embora ela não explicite uma identificação da DA com a disciplina, acrescentando outros elementos, ela está presente também em seu discurso.

A abordagem que mais se aproxima da sua concepção de DA é a abordagem afetiva. A docente prioriza, em seu discurso, problemas socioafetivos das crianças. 


\section{Confronto de concepções nos programas}

Como já anunciamos anteriormente, aplicamos o mesmo procedimento de análise das concepções, apresentado no programa 1, aos programas 2 e 3.

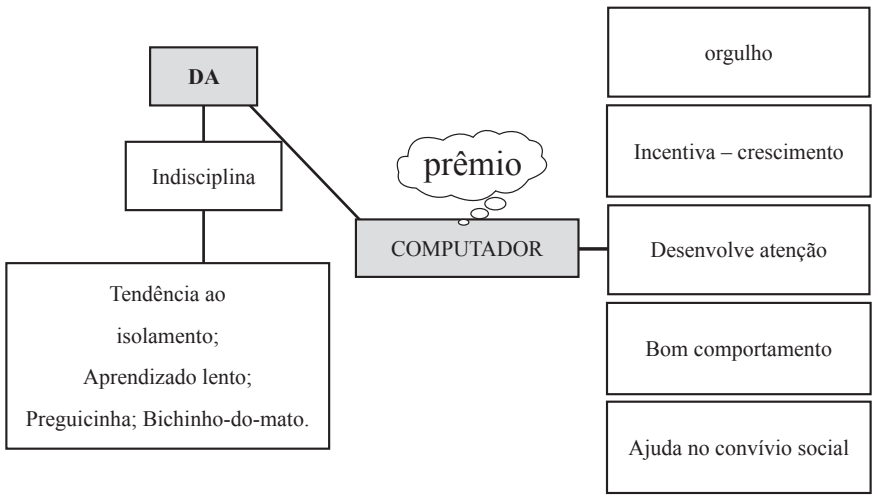

\section{Programa 1}

No programa 1, identificamos dois discursos bastante conflituosos. Possivelmente a distribuição de papéis no programa tenha contribuído para que eles estivessem presentes nos discursos dos demais sujeitos. O esquema abaixo mostra a zona de conflito entre os diferentes discursos (coordenador $\mathrm{X}$ professores). Através dele, podemos visualizar esse movimento.

No esquema, representamos à esquerda as concepções do coordenador do programa e, à direita, o discurso dos professores, que identificamos serem muito próximos entre si, porém contraditórios com o do coordenador. À esquerda, existe DA e o computador

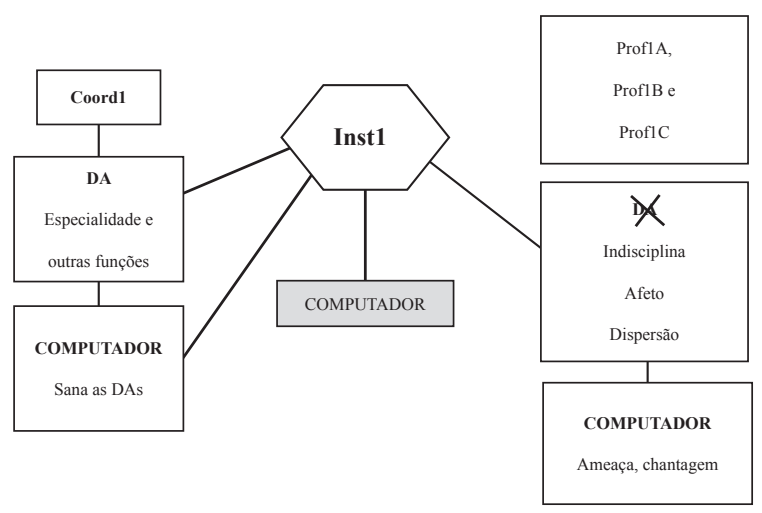
ajuda a saná-la. À direita, 
não existe DA e o computador ajuda como instrumento para disciplinar os alunos.

A Inst1 tem a mesma concepção de DA das professoras, de que esta não existe, e o que existe são problemas de indisciplina, ao mesmo tempo que afirma que as DAs estão relacionadas à espacialidade, como fala a Coord1. Seu discurso é, portanto, contraditório guardando elementos dos outros dois. Quanto ao uso do computador para superar DA, a Inst1 aproxima-se da concepção da Coord1, de que o computador sana DA.

As professoras regentes distanciam-se completamente da concepção da Coord1. Mas ganham a adesão da Inst1, sobre o tema indisciplina. A Inst1 é a única personagem que aponta uma dimensão pedagógica para a utilização do computador na aprendizagem dos alunos.

\section{Programa 2}

No cruzamento dos discursos de Orient 2 e $A 2$, destacamos os elementos centrais de suas concepções e os representamos através do esquema ao lado, para depois os compararmos às concepções dos outros sujeitos. Esses dois sujeitos estão hierarquicamente acima dos professores e da instrutora na escola. $\mathrm{O}$ discurso de $A 2$ apresenta a DA como algo que alimenta o processo de aprendizagem, enquanto Orient 2 vê a DA como algo a ser sanado. Além disso, o uso do computador é visto, por $A 2$, como integrado ao processo de aprendizagem, diferentemente de Orient2, que vê sua presença apenas como motivador do processo. São

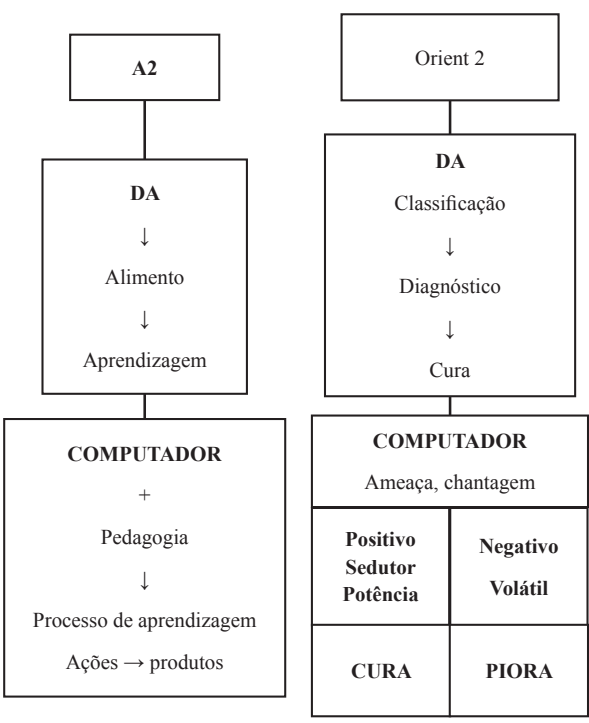
concepções bastante distantes.

Cruzamos, em seguida, as informações acima com os discursos dos demais participantes. O confronto entre as concepções de todos os sujeitos do programa mostra forte influência dos anteriormente comentados. 


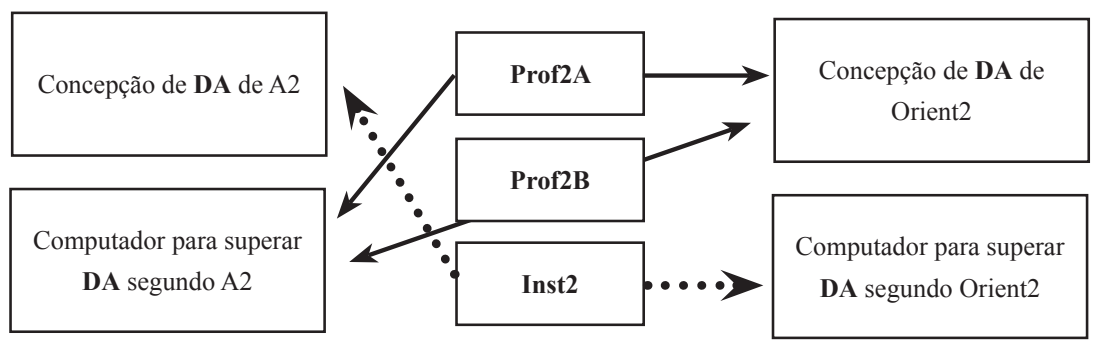

A concepção de DA das professoras mostrou-se ligada à de Orient2 e, quanto ao uso do computador para superar DA, sua concepção aproxima-se de A2. Já Inst2 faz um caminho inverso, aproxima-se da concepção de $A 2$ quanto àa $\mathrm{DA}$ e, sobre o uso do computador para superar $\mathrm{DA}$, recebeu maior influência da concepção de Orient2.

\section{Programa 3}

Os discursos do programa 3 apresentam contradições. Porém, por haver somente dois sujeitos, não houve possibilidade de situarmos tão bem seus papéis.

O conflito está nitidamente na concepção de DA, como podemos observar através do esquema a seguir.

Para, a instrutora, não há DA. O problema fica remetido a outras esferas: pais, escola pública, sala de aula cansativa. A metáfora O COMPUTADOR É UM SHOPPING reafirma o computador agindo numa dimensão emocional e afetiva dos alunos.

Já, para Prof3, existe DA. A metáfora O COMPUTADOR É UM PRESENTE QUE CAIU DOS CÉUS afirma o computador como algo mágico. A metáfora da batalha afirma a vitória contra o mal DA. O computador age positivamente na escolaridade e na disciplina. 


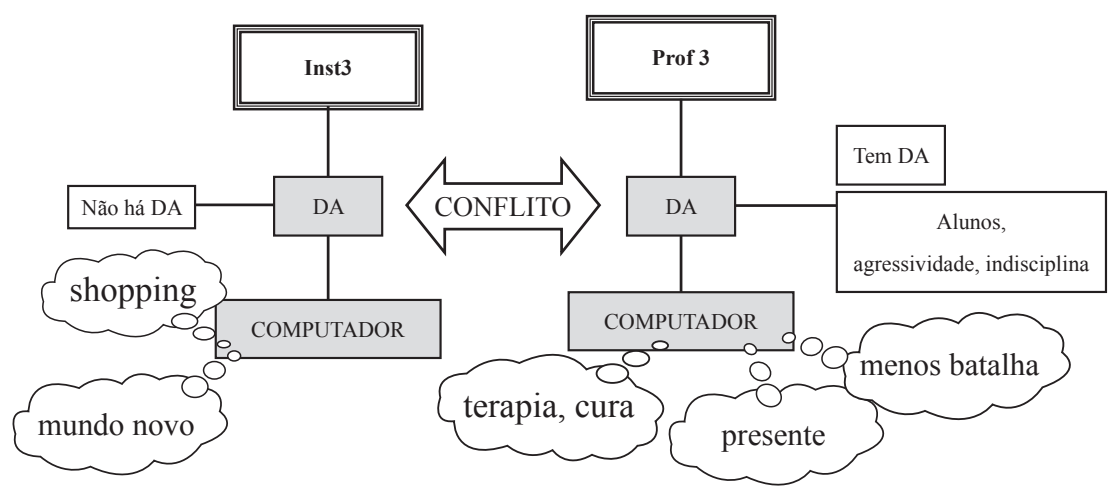

\section{Considerações finais}

O confronto dos discursos entre os participantes de um mesmo programa revelou distanciamentos tanto em relação ao que se concebe por DA, quanto à expectativa depositada no computador para superá-la. Com relação à DA, apareceu nitidamente um problema de identificação da dificuldade. Quem tem dificuldade: a criança, os pais, a escola, o professor, o instrutor ou os profissionais da educação e psicologia que atuam na escola? Os discursos sobre essa autoria comportaram ambigüidades e até mesmo contradições.

Com relação ao computador, as justificativas para seu uso, quando apareceram, eram muito distantes entre si, porém, coerentes com as concepções de DA apresentadas pelos sujeitos. Quando a DA dos alunos dizia respeito à indisciplina, o computador apareceu como disciplinador; quando dizia respeito à relação da criança com sua lateralidade, o computador apareceu como um espelho, como uma ferramenta para trabalhar os elementos do espaço; quando a DA alimentava a aprendizagem; o computador era um motor para essa aprendizagem, quando a DA se identificava com auto-estima e afetividade, o computador era uma máquina carinhosa, e assim por diante. 
No interior de cada um dos programas, não conseguimos encontrar notáveis conciliações. No entanto, quando foram comparadas as concepções dos sujeitos dos três programas, tendo como critério o mesmo papel e atribuição, encontramos alguns elementos conciliadores. Os professores atribuem a culpa das dificuldades aos seus alunos e/ou às suas famílias, eximindo-se de qualquer responsabilidade, como já fora concluído em outro estudo (ALVES-MAZZOTTI, 2003). Os instrutores atribuem a culpa ao professor, com sua inadequação metodológica, à rigidez da burocracia escolar ou ao ambiente familiar. Também eximem-se de alguma responsabilidade. Não havendo um núcleo comum para os coordenadores, apontamos a concepção com maior adesão: a culpabilização da DA tende a cair sobre o professor ou na dificuldade da estrutura escolar em lidar com os vários ritmos de aprendizagem de seus alunos.

Os resultados levaram-nos a inferir que o não-aprender está bastante relacionado a um desconhecimento de como se dá a aprendizagem pelos educadores de maneira geral. $\mathrm{O}$ fato de as abordagens teóricas aparecerem mescladas no discurso dos idealizadores dos programas fortalece nossa conclusão, uma vez que os demais envolvidos diante das que estes exerçam um papel de liderança na condução das propostas.

Para as crianças da classe popular são oferecidos programas compensatórios, tendo em vista superar suas dificuldades, suprir suas carências. Porém, seu professor já minimizou a expectativa quanto ao aluno, que ele indicou como portador de $\mathrm{DA}$, com critérios subjetivos, geralmente relacionados à disciplina em sala de aula. Não menos subjetivos foram os critérios utilizados pelos envolvidos com as novas propostas de utilização da tecnologia para sanar a DA.

Os resultados desta investigação nos levam a pensar sobre a importância de compreender de quem é e o que é dificuldade de aprendizagem, e que essa questão poderá ser melhor entendida a partir de uma maior reflexão sobre a relação teoria x prática escolar. $\mathrm{O}$ fato de as concepções dos diversos envolvidos em um mesmo programa distanciarem-se muito, por si só, já denuncia a pouca compreensão dos processos do aprender e a pouca coerência entre as propostas de uso do computador e os modelos explicativos do problema. É preciso também que se compreenda se a presença do computador é uma estratégia para fazer face a necessidades pedagógicas ou se se trata de um mito, em que o valor maior recai meramente na modernização. 


\section{REFERÊNCIAS}

ALVES-MAZZOTTI, Alda Judith. Representações de professores sobre o "fracasso escolar”. In: REUNIÃO ANUAL ANPED, 26., Poços de Caldas, 2003. Anais... Poços de Caldas, 2003. CD-ROM.

CARVALHO, Rosita Edler. Atendimento educacional especializad, em organizações governamentais de ensino, para alunos que apresentam distúrbio de aprendizagem: discurso e prática. 184 f. Tese (Doutorado em Educação) - Faculdade de Educação da Universidade Federal do Rio de Janeiro, Rio de Janeiro, 1996.

CASTANHEIRA, M. Lúcia; SANTIAGO, Ana Lydia. Oralidade e escrita: dificuldades de ensino-aprendizagem na alfabetização. Disponível em: <http://www.tvebrasil.com. br/salto/boletins2004/ale/tetxt2.htm>. Acesso em: 16/6/2004.

CASTRO, Monica Rabello de et al. O conceito de montagem para análise e compreensão do discurso. Boletim GEPEM, Rio de Janeiro, v. 44, 2004.

CASTRO, M. R.; FRANT, Janete B.; KINDEL, D. Soraia. Estratégia argumentativa: um modelo para a pesquisa de sala de aula. In: ENDIPE, 10., Rio de Janeiro, 2001. Anais... Rio de Janeiro, 2001.

GAUTHIER, Jacques Z. A questão da metáfora, da referência e do sentido em pesquisas qualitativas: o aporte da sociopoética. Revista Brasileira de Educação, Rio de Janeiro, n. 25, p. 127-142, jan./abr. 2004.

GOMES, M. F. Cardoso. Leitura e escrita: a produção dos "maus" e "bons" alunos. In: GOMES, M. F. Cardoso; SENA, M. das Graças de Castro. (Org.). Dificuldades de aprendizagem na alfabetização. 2. ed. Belo Horizonte: Autêntica, 2002. p. 9-28.

MAZZOTTI, Tarso Bonilha; OLIVEIRA, Renato José. Ciência(s) da educação. Rio de Janeiro: DP\&A, 2000.

SILVA, Maria Cristina da. Saberes e dizeres de crianças que "fracassam" na escola. In: VALENTE, José A. et al. O computador na sociedade do conhecimento. Coleção PROINFO, v. 2. Brasília: MEC, 1989. Disponível em: <www.inf.ufsc.br/ edla/mec/ colecaoproinfo $>$. Acesso em: 21/3/2004. 
SOARES, Magda. Linguagem e escola: uma perspectiva social. 15. ed. São Paulo: Ática, 1997.

WEISS, Alba M. Lemme; CRUZ, Mara L. R. Monteiro da. A informática e os problemas escolares de aprendizagem. 3. ed. Rio de Janeiro: DP\&A, 2001.

Texto recebido em 18 jan. 2007 Texto aprovado em 4 jun. 2007 